\title{
Weight does Matter! A Study of Effect of Obesity on Pregnancy and its Outcome
}

\author{
Anupama Dave, Laxmi Maru, Shraddha Daksha, Neeta Natu
}

\section{ABSTRACT}

Objectives: To analyze the significant risk associated with obesity and its consequences on obstetrics management and perinatal outcome.

Materials and methods: A prospective study was carried out in the Department of Obstetric and Gynecology, MGM Medical College and My Hospital, Indore. The study enrolled 200 pregnant women with body mass index $(\mathrm{BMI})>25$ and equal number of women with normal BMI (18-24.9) as control.

Results: A total of 76 (38\%) out of 200 pregnant women were overweight, 70 (35\%) were obese type 1 (BMI: 30-34.9), 44 (22\%) had BMI (35-39.9) and $10(5 \%)$ had $\mathrm{BMI}>40$. In comparison to normal BMI pregnant women, women with BMI $>25$ had significant risk of gestation hypertension $(p=0.004)$, pre-eclampsia $(p=0.04)$ gestational diabetes mellitus and shoulder dystocia $(p=0.021)$, cesarean section $(0.0001)$, induced labor (0.0001) and decreased incidence of VBAC $(p=0.037)$ with postoperative wound infection. Neonates of these women were mostly macrosomic $(p=0.021)$ and had high incidence of shoulder dystocia.

Conclusion: High maternal BMI at booking is associated with increased risk of pregnancy complications. Achieving a normal BMI prior to conception with the institution of healthy eating and exercise regimens may represent an ideal option.

Keywords: Body mass index, Obesity, Macro somia.

How to cite this article: Dave A, Maru L, Daksha S, Natu N. Weight does Matter! A Study of Effect of Obesity on Pregnancy and its Outcome. J South Asian Feder Obst Gynae 2013;5(3): 107-110.

Source of support: Nil

Conflict of interest: None declared

\section{INTRODUCTION}

The growing epidemic of obesity in our society has become a major public health issue, with serious social and psychological consequences in addition to the physical health implications. Obesity has reached epidemic proportions globally with a similar rise in prevalence among women in the reproductive age group. This has critical consequences for fetal and maternal health in the antepartum, intrapartum and postpartum periods. Maternal obesity is defined according to the World Health Organization and National Institute of Health guidelines as follows: overweight, body mass index (BMI): 25 to $29.9 \mathrm{~kg} / \mathrm{m}^{2}$ or obese, BMI $>30 \mathrm{~kg} / \mathrm{m}^{2}$.

Obesity has significant consequences for the reproductive system, depending upon the amount and distribution of body fat. Epidemiological evidence clearly shows that being overweight contributes to menstrual disorders, infertility, an increased risk of a number of serious adverse pregnancy outcomes, including miscarriage, fetal congenital anomaly, thromboembolism, gestational diabetes, pre-eclampsia, dysfunctional labor, postpartum hemorrhage wound infections, stillbirth and neonatal death. There is a higher cesarean section rate and lower breastfeeding rate in this group of women compared to women with a healthy BMI. There is also evidence to suggest that obesity may be a risk factor for maternal death: the confidential enquiry into maternal and child health report on maternal deaths in the 2003 to 2005 triennium showed that $28 \%$ of mothers who died were obese, whereas the prevalence of obesity in the general maternity population within the same time period was 16 to $19 \% .^{2}$

\section{OBJECTIVES}

The present study aims to evaluate the comparison between normal BMI pregnant women and women with BMI $>25$ and its effect on maternal and perinatal outcome.

\section{MATERIALS AND METHODS}

A prospective study was conducted in the Department of Obstetrics and Gynecology, Mahatma Gandhi Medical College and Maharaja Yeshwantrao Hospital, Indore, extending from a Jan 2010 to Feb 2011. The study group comprised of 200 singleton pregnant women with BMI $>25$ and control group comprising of 200 singleton pregnant women with BMI 18 to 24.9 at the time of admission in indoor wards. Inclusion criteria for the study group was pregnant women with BMI $>25$ at the time of admission, singleton pregnancy and $>28$ weeks of gestation. Exclusion criteria included women with previous two cesarean, multiple pregnancy and pregnancy with medical disorders. Detailed history regarding age, parity, socioeconomic status, residence, duration of pregnancy, $\mathrm{h} / \mathrm{o}$ primary infertility and family history of obesity was taken. BMI was calculated as weight $(\mathrm{kg})$ divided by height $\left(\mathrm{m}^{2}\right)$ at the time of admission; general examination including abdominal girth, blood pressure, urine albumin, along with obstetric examination with pelvic assessment was done at the time of labor.

Cases were grouped into five on the basis of BMI.

Group I: 18 to 24.9 (control)

Group II: 25 to 29.9 (overweight)

Group III: 30 to 34.9 (obesity class I)

Group IV: 35 to 39.9 (obesity class II)

Group V: $>40$ (obesity class III)

Pregnancy-related complications, mode of delivery as normal labor, induced labor, preterm labor (PTL), cesarean or assisted instrumental delivery and vaginal birth after cesarean, anesthesiarelated complications and perinatal outcome was seen and these outcome variables of overweight and obese group were compared with control group (women with normal BMI). 


\section{STATISTICAL ANALYSIS}

Statistical analysis was performed using Chi-square test between cases and control for different variables. The $p$-value $<0.05$ was considered to be statistically significant.

\section{RESULTS}

Certain epidemiological factors including age, parity, religion, residential area, educational status, family history of obesity and primary infertility were analyzed and maternal and perinatal outcome was studied in obese pregnant women with BMI $>25$ at the time of admission and compared to normal BMI controls (18-24.9).

The following conclusions were drawn:

- In the present study, the incidence of obesity was found to be more common in 26 to 35 years age group (58\%) and majority of cases were nulliparous (53\%).

- Most of the cases in the study belong to urban areas (65\%) and majority of obese were nonvegetarian (82\%).

- Family history of obesity and primary infertility was more common in obese group.

- Incidence of gestational hypertension (22\%), pre-eclampsia (13\%), gestational diabetes mellitus (GDM: $2 \%$ ), shoulder dystocia (2\%) was found to be increased in women with $\mathrm{BMI}>25$, which is statistically significant.

- Mode of delivery for obese women was mostly cesarean $(52 \%)(\mathrm{p}=0.0001)$ with commonest indication being failed induction, others were cephalopelvic disproportion, previous cesarean section.

- Success of vaginal birth after cesarean (VBAC) decreased with increasing BMI ( $\mathrm{p}=0.037)$.

- Anesthesia-related complications were more frequently seen in cases with BMI $>25$ as difficulty in venous access (6\%), difficulty in palpating space, and multiple pricks in regional anesthesia which is statistically significant $(\mathrm{p}=0.0001)$.

- Wound disruption was more seen in obese including seroma, abscess, fascial dehiscence, episiotomy wound gaping $(\mathrm{p}=0.02)$.
- Obesity significantly affects the perinatal outcome with macrosomia incidence being $2 \%$ only seen in obese group $(\mathrm{BMI}>30)$.

\section{DISCUSSION}

Two hundred cases with BMI $>25$ were studied, apart from routine investigation BMI was calculated at the time of admission. Antenatal, intranatal and postnatal events of both study and control groups were observed and analyzed.

Age: In the present study, $116(58 \%)$ patients of study group and $84(42 \%)$ patients in control group were in 26 to 35 years of age group (Table 1).

Parity: A total of 106 (53\%) patients of study group and $84(42 \%)$ patients in control group were nulliparous.

Residential status: In our study, 133 (66.5\%) belonged to urban areas whereas 53\% control belonged to urban area. Migration from rural to urban areas is associated with increasing levels of obesity and is a factor driving the diabetes epidemic in India. ${ }^{3}$

Associated maternal complications: In our study (Table 2), it was evident that gestational hypertension were found in $44(22 \%)$ women as compared to BMI $<25$ where it is only $11 \%(\mathrm{p}=0.004)$. Pre-eclampsia was found in $26(13 \%)$ patients of study group whereas $13(6.5 \%)$ in control group (p $=0.04)$. Cnattingius $(1998)^{4}$ showed that the rate of preeclampsia increases with an increasing BMI. Catalano et al $(2006)^{5}$ found that obese women and morbidly obese women were 2.5 and 3.2 times (respectively) more likely to develop gestational hypertension than the control group. Similarly, preeclampsia was 1.6 and 3.3 times more likely to develop in obese and morbidly obese women, respectively. Obese women had a tendency to develop GDM. Obese women had a significant risk for gestational diabetes. ${ }^{6}$ Overweight is a risk factor for impairment of carbohydrate tolerance. In our study, GDM was seen in $4(2 \%)$ women, predominantly in obese group with BMI $>30(p=0.021)$. Debasmita et al $(2010)^{7}$ compared the average weight of pregnant women with obese pregnant women and concluded that obese pregnant women were at increased risk of GDM (19.43 vs 3.79\%; $<<0.001)$, pregnancy-induced

\begin{tabular}{cccccc}
\multicolumn{7}{c}{ Table 1: Demographic profile of cases } \\
\hline Age (years) & $\begin{array}{c}\text { No. of cases } \\
(n=200)\end{array}$ & Parity & $\begin{array}{c}\text { No. of cases } \\
(n=200)\end{array}$ & Residence & $\begin{array}{c}\text { No. of cases } \\
(n=200)\end{array}$ \\
\hline $18-25$ & $70(35 \%)$ & Primiparity & $106(53 \%)$ & Urban & $133(66.5 \%)$ \\
$26-35$ & $109(54.5 \%)$ & Multiparity & $94(47 \%)$ & Rural & $67(33.3 \%)$ \\
$>35$ & $21(10.5 \%)$ & & & \\
\hline
\end{tabular}

\begin{tabular}{|c|c|c|c|c|c|c|}
\hline \multirow[t]{2}{*}{ Variable } & \multicolumn{5}{|c|}{ Cases } & \multirow[t]{2}{*}{$p$-value } \\
\hline & $\begin{array}{l}\text { Group I } \\
\text { (control) } \\
(n=200)\end{array}$ & $\begin{array}{l}\text { Group II } \\
(n=76)\end{array}$ & $\begin{array}{l}\text { Group III } \\
(n=70)\end{array}$ & $\begin{array}{l}\text { Group IV } \\
(n=44)\end{array}$ & $\begin{array}{l}\text { Group V } \\
(n=10)\end{array}$ & \\
\hline $\begin{array}{l}\text { Gestational } \\
\text { hypertension }\end{array}$ & $22(11 \%)$ & $16(21 \%)$ & $12(17.1 \%)$ & $10(22.7 \%)$ & $6(60 \%)$ & 0.004 \\
\hline Pre-eclampsia & $13(6.5 \%)$ & $8(10.5 \%)$ & $6(8.5 \%)$ & $8(18.1 \%)$ & $4(40 \%)$ & 0.04 \\
\hline $\begin{array}{l}\text { Gestational } \\
\text { diabetes mellitus }\end{array}$ & $0(0 \%)$ & $0(0 \%)$ & $1(1.4 \%)$ & $2(47.5 \%)$ & $1(10 \%)$ & 0.021 \\
\hline Shoulder dystocia & $0(0 \%)$ & $0(0 \%)$ & $1(1.4 \%)$ & $1(2.2 \%)$ & $2(20 \%)$ & 0.021 \\
\hline
\end{tabular}


hypertension $(12.32$ vs $2.36 \%$; $<<0.001)$ and pre-eclampsia (8.76 vs 3.31\%; $\mathrm{p}<0.001)(\mathrm{p}=0.0004)$.

Mode of delivery: From observation (Table 3), it is clear that obese pregnant women were more likely to be delivered by cesarean section. A total of $104(52 \%)$ cases out of 200 were taken for cesarean section as compared to $27 \%$ in normal BMI cases $(p=0.0001)$. Weiss et al $(2004)^{8}$ showed that the cesarean delivery rate was $20.7 \%$ for the control group, $33.8 \%$ for obese and $47.4 \%$ for morbidly obese patients. Rate of labor induction was also higher in women with higher BMI, 23.5\% as compared to $6 \%$ in BMI $<25(\mathrm{p}=0.0001)$. ${ }^{7}$ Obese women had a significantly higher rate of IOL ending in cesarean section compared with women of normal weight following IOL, 38.7 vs $23.8 \%$ primiparous; 9.9 vs $7.9 \%$ multiparous women, respectively. ${ }^{9}$ In our study, the incidence of VBAC was nil in obese group but 8 (4\%) women had VBAC in the control group, which is significant $(p=0.037)$. Durnwald et al $(2004)^{10}$ showed that the greatest success rate for VBAC was in underweight $(\mathrm{BMI}<19.8)$ women $(84.7 \%)$ as compared with those in normal weight women $(\mathrm{p}=0.04)$. Decreased VBAC success was observed in obese women $(54.6 \%)$ but not in overweight women $(65.5 \%)$ compared with normal weight women $(70.5 \%)$ $(p=0.003$ and $p=0.36$, respectively). Incidence of shoulder dystocia was $2 \%$ among obese group $(p=0.021) .{ }^{11}$ No significant differences were noticed in the occurrence of PTL and operative vaginal delivery.

Anesthesia-related complication: As per Table 4, we can conclude that $6 \%$ (12 out of 200) cases had difficulty in venous access, $8.5 \%$ cases had difficulty in palpation of space in regional anesthesia and $8 \%$ cases among obese patient had more than three attempt for skin prick in regional anesthesia as compared to $7 \%$ control with BMI $<25$ which is significant $(\mathrm{p}=0.0001){ }^{12}$

Postnatal complication: From the observation (Table 5), it is clear that wound disruption is more common in obese class III patient, i.e. $10 \%$ as compared to $1.5 \%$ in normal BMI cases $(\mathrm{p}=0.002)$. The increased cesarean rate in overweight and obese women is also associated with an increase in postoperative complications such as wound infection/ breakdown, excessive blood loss and postpartum endometritis. ${ }^{10}$ No significant differences were seen in the incidence of primary postpartum hemorrhage.

Perinatal outcome: As seen in Table 6, incidence of macrosomia was common in obese group and none of the cases were seen in normal BMI group. No significant differences were noted in neonatal complication, IUGR and low birth babies. HAPO study $(2010)^{13}$ showed that higher maternal BMI was associated with increased frequency of birth weight $>90$ th percentile.

\section{CONCLUSION}

Obesity is a major global problem that will not only get worse if we do not act without further delay and with a sense of urgency. ${ }^{14}$ The literature has established that maternal obesity is increasing globally. Maternal obesity has been shown to

\begin{tabular}{|c|c|c|c|c|c|c|}
\hline \multirow[t]{2}{*}{ Mode of delivery } & \multicolumn{5}{|c|}{ Cases } & \multirow[t]{2}{*}{$p$-value } \\
\hline & $\begin{array}{c}\text { Group I (control) } \\
(n=200)\end{array}$ & $\begin{array}{l}\text { Group II } \\
(n=76)\end{array}$ & $\begin{array}{l}\text { Group III } \\
(n=70)\end{array}$ & $\begin{array}{l}\text { Group IV } \\
(n=44)\end{array}$ & $\begin{array}{l}\text { Group V } \\
(n=10)\end{array}$ & \\
\hline NL & $114(57 \%)$ & $20(26.3 \%)$ & $15(21.4 \%)$ & $4(9 \%)$ & $0(0 \%)$ & - \\
\hline Induced labor & $12(6 \%)$ & $17(22.3 \%)$ & $20(28.5 \%)$ & $9(20.4 \%)$ & $1(10 \%)$ & 0.0001 \\
\hline Cesarean & $54(27 \%)$ & $33(43.4 \%)$ & $32(45.7 \%)$ & $29(65.9 \%)$ & $8(80 \%)$ & 0.0001 \\
\hline $\begin{array}{l}\text { Operative vaginal } \\
\text { delivery }\end{array}$ & $4(2 \%)$ & $0(0 \%)$ & $2(2.8 \%)$ & $2(4.5 \%)$ & $1(10 \%)$ & - \\
\hline PTL & $8(4 \%)$ & $5(6.5 \%)$ & $1(1.4 \%)$ & $0(0 \%)$ & $0(0 \%)$ & - \\
\hline VBAC & $8(4 \%)$ & $1(1.3 \%)$ & $0(0 \%)$ & $0(0 \%)$ & $0(0 \%)$ & 0.037 \\
\hline
\end{tabular}

\begin{tabular}{|c|c|c|c|c|c|c|}
\hline \multirow{2}{*}{$\begin{array}{l}\text { Anesthesia-related } \\
\text { complications }\end{array}$} & \multicolumn{5}{|c|}{ Cases } & \multirow[t]{2}{*}{$p$-value } \\
\hline & $\begin{array}{c}\text { Group I (control) } \\
(n=200)\end{array}$ & $\begin{array}{l}\text { Group II } \\
(n=76)\end{array}$ & $\begin{array}{l}\text { Group III } \\
(n=70)\end{array}$ & $\begin{array}{l}\text { Group IV } \\
(n=44)\end{array}$ & $\begin{array}{l}\text { Group V } \\
(n=10)\end{array}$ & \\
\hline $\begin{array}{l}\text { Difference } \\
\text { in venous access }\end{array}$ & $2(1 \%)$ & $1(1.3 \%)$ & $1(1.4 \%)$ & $4(9 \%)$ & $6(60 \%)$ & \\
\hline $\begin{array}{l}\text { Difference } \\
\text { in palpating space }\end{array}$ & $6(3 \%)$ & $1(1.3 \%)$ & $4(5.7 \%)$ & $4(9 \%)$ & $8(80 \%)$ & 0.0001 \\
\hline Skin prick in $R A>1$ & $6(3 \%)$ & $2(2.6 \%)$ & $10(14.2 \%)$ & $8(18.1 \%)$ & $4(40 \%)$ & \\
\hline$>3$ & $0(0 \%)$ & $0(0 \%)$ & $2(2.8 \%)$ & $4(9 \%)$ & $2(20 \%)$ & \\
\hline
\end{tabular}

Overall $(p=0.0001)$

Table 5: Distribution of cases and postnatal complications

\begin{tabular}{lcccccc}
\multicolumn{7}{c}{ Table 5: Distribution of cases and postnatal complications } \\
\hline Postnatal & \multicolumn{7}{c}{ Cases } & p-value \\
complications & $\begin{array}{c}\text { Group I (control) } \\
(n=200)\end{array}$ & $\begin{array}{c}\text { Group II } \\
(n=76)\end{array}$ & $\begin{array}{c}\text { Group III } \\
(n=70)\end{array}$ & $\begin{array}{c}\text { Group IV } \\
(n=44)\end{array}$ & $\begin{array}{c}\text { Group V } \\
(n=10)\end{array}$ & - \\
PPH & $4(2 \%)$ & $2(2.6 \%)$ & $2(2.8 \%)$ & $1(2.2 \%)$ & $1(10 \%)$ & 0.14 \\
Wound disruption & $3(1.5 \%)$ & $2(2.6 \%)$ & $3(4.2 \%)$ & $2(4.5 \%)$ & $2(20 \%)$ & \\
\hline
\end{tabular}




\begin{tabular}{lclcccc}
\multicolumn{7}{c}{ Table 6: Distribution of cases and perinatal outcome } \\
\hline Outcome & \multicolumn{7}{c}{ Cases } \\
\cline { 2 - 5 } & $\begin{array}{c}\text { Group I (control) } \\
(n=200)\end{array}$ & $\begin{array}{l}\text { Group II } \\
(n=76)\end{array}$ & $\begin{array}{c}\text { Group III } \\
(n=70)\end{array}$ & $\begin{array}{c}\text { Group IV } \\
(n=44)\end{array}$ & $\begin{array}{c}\text { Group V } \\
(n=10)\end{array}$ & -value \\
LBW $(<2.5 \mathrm{~kg})$ & $28(14 \%)$ & $6(7.8 \%)$ & $3(4.2 \%)$ & $2(4.5 \%)$ & $0(0 \%)$ & - \\
Macrosomia $>4 \mathrm{~kg}$ & $0(0 \%)$ & $0(0 \%)$ & $1(1.4 \%)$ & $1(2.2 \%)$ & $2(20 \%)$ & 0.021 \\
IUD/stillbirth & $9(4.5 \%)$ & $1(1.3 \%)$ & $1(1.4 \%)$ & $2(4.5 \%)$ & $1(10 \%)$ & 0.7 \\
IUGR & $14(7 \%)$ & $3(3.9)$ & $2(2.8 \%)$ & $1(2.2 \%)$ & $0(0 \%)$ & - \\
Neonatal & $15(7.5 \%)$ & $5(6.5 \%)$ & $4(5.7 \%)$ & $3(6.8)$ & $1(10 \%)$ & - \\
complications & & & & & & \\
\hline
\end{tabular}

increase the incidence of morbidity and mortality during pregnancy and the puerperium. All obstetricians and midwives must be aware of the potential complications in women with obesity.

A care plan is indicated as an approach to target this growing health problem. Ideally, obesity should be addressed before conception and as early as in childhood. In our care plan, we should outline the major areas for providing a high standard of obstetric care in these high risk women. In the antenatal period, women should be seen in a consultant's clinic for their booking antenatal appointment and monitored during the pregnancy. Emphasis should be made on good nutrition, exercise, prevention and treatment of pregnancy-related disorders, anesthetic review and the provision of appropriate equipment. During labor, the assessment by a senior obstetrician should be made and particular attention paid to the progress of labor, process of induction of labor and aspects of the surgical technique of cesarean sections. Postpartum support cannot be overlooked and women should be assessed particularly for venous thromboembolism and psychological disorders. With the additional weight gained from the pregnancy, postpartum obese women must be encouraged to visit the dietician, exercise, commence a weight management program and use contraception. ${ }^{13}$

\section{REFERENCES}

1. National Institute for Health and Clinical Excellence. Obesity: Guidance on the prevention, identification, assessment and management of overweight and obesity in adults and children. London: National Institute for Health and Clinical Excellence (NICE); Dec 2006.

2. Lewis G. Confidential Enquiry into Maternal and Child Health. Saving mothers' lives-Reviewing maternal deaths to make motherhood safer 2003-2005. London: CEMACH; 2007. CMACE/RCOG Joint Guideline: management of women with obesity in pregnancy. 2010 Mar. 19 p.

3. Ebrahim S, Kinra S, Bowen L, Andersen E, Ben-Shlomo Y. The effect of rural-to-urban migration on obesity and diabetes in India: a cross-sectional study. PLoS Med 2010 May; 7(4):e1000268.

4. Cnattingius S, Bergström R, Lipworth L, Kramer MS Prepregnancy weight and the risk of adverse pregnancy outcomes. N Engl J Med 1998 Jan;338(3):147-152.

5. Catalano P, Ehrenberg HM. The short and long-term implications of maternal obesity on the mother and her offspring. BJOG 2006 Oct;113(10):1126-1133.

6. Sahu MT, Agarwal A, Das V, Pandey A. Impact of maternal body mass index on obstetric outcome. J Obstet Gynaecol Res 2007 Oct;33(5):655-659.
7. Mandal D, Manda S, Rakshi A, Dey RP, Biswas SC, Banerjee A. Maternal obesity and pregnancy outcome: a prospective analysis. J Assoc Physicians India 2011 Aug;59:486-489.

8. Weiss JL, Malone FD, Emig D, Ball RH, Nyberg DA, Comstock CH, Saade G, Eddleman K, Carter SM, Craigo SD, et al. Obesity, obstetric complications and cesarean delivery rate-a population based screening study. Am J Obstet Gynecol 2004 Apr; 190(4):1091-1097.

9. Arrowsmith S, Wray S, Quenby S. Maternal obesity and labour complications following induction of labour in prolonged pregnancy. BJOG $2011 \mathrm{Apr} ; 118(5) ; 578-588$.

10. Durnwald CP, Ehrenberg HM, Mercer BM. The impact of maternal obesity and weight gain on vaginal birth after cesarean section success. Am J Obstet Gynecol 2004 Sep;191(3):954-957.

11. Usha Kiran TS, Hemmadi S, Bethel J, Evans J. Outcome of pregnancy in a woman with an increased body mass index. BJOG 2005 Jun;112(6):768-772.

12. Rao DP, Rao VA. Morbidly obese parturient: challenges for the anaesthesiologist including managing the difficult airway in obstetrics. What is new? Indian J Anaesth 2010 Nov;54(6): 508-521.

13. HAPO Study Cooperative Research Group. Hyperglycaemia and Adverse Pregnancy Outcome (HAPO) Study: associations with maternal body mass index. BJOG 2010 Apr;117(5):575-584.

14. Controlling the global obesity epidemic. Geneva, Switzerland: WHO health topics; 2004. Available from: www.who.int/nut/ obs.htm. Accessed: 5 July 2005.

\section{ABOUT THE AUTHORS}

\section{Anupama Dave}

Associate Professor, Department of Obstetrics and Gynecology, MY Hospital and MGM Medical College, Indore, Madhya Pradesh, India

Correspondence Address: 314, Saket Nagar, Indore, Madhya Pradesh, India, Phone: 09425053230, e-mail: arvinddave10@ yahoo.co.in

\section{Laxmi Maru}

Professor and Head, Department of Obstetrics and Gynecology, MY Hospital and MGM Medical College, Indore, Madhya Pradesh, India

\section{Shraddha Daksha}

Resident (3rd year), Department of Obstetrics and Gynecology, MY Hospital and MGM Medical College, Indore, Madhya Pradesh, India

\section{Neeta Natu}

Assistant Professor, Department of Obstetrics and Gynecology, Sri Aurobindo Institute of Medical Sciences, Indore, Madhya Pradesh India 